Universidad Nacional de La Plata.

Facultad de Humanidades y Ciencias de la Educación.

Centro de Investigaciones Socio Históricas

\title{
El movimiento estudiantil de la Universidad de Buenos Aires en el final de la última dictadura (1982-83)
}

\author{
Student movement at the University of Buenos Aires in the end of \\ Argentina's last dictatorship (1982-83)
}

\section{Cristal Yann *}

* Facultad de Filosofía y Letras - Universidad de Buenos Aires, Argentina I ycristal@yahoo.com

\section{PALABRAS CLAVE}

Movimiento estudiantil

Universidad de Buenos Aires

Dictadura

Posdictadura

\section{RESUMEN}

En este trabajo investigamos la reactivación del movimiento estudiantil de la Universidad de Buenos Aires entre 1982 y 1983, y su relación con la dinámica del conflicto social, del mundo universitario y de la política general de la Argentina en el final de la última dictadura. Nos concentramos tanto en los procesos de movilización como en la reorganización de los centros de estudiantes tras años de proscripción. En ese contexto, la reaparición de ciertas prácticas vinculadas a las décadas precedentes se combinó con una valoración crítica del movimiento estudiantil sobre su pasado reciente, bajo la nueva hegemonía de Franja Morada que se nutrió y a la vez incidió en el avance del alfonsinismo y la consolidación de un nuevo "ideal democrático". A partir de estas cuestiones, este artículo se propone aportar elementos en el sentido decomplejizar la relación entre factores de continuidad y cambio en los inicios de la posdictadura.

\section{KEYWORDS}

Student movement

University of Buenos Aires

Military dictatorship

Post-dictatorship

\begin{abstract}
In this article we investigate the revival of the student movement at the University of Buenos Aires between 1982 and 1983, and its relationship to the dynamics of social conflict, the University environment and the general politics of Argentina at the end of its last military dictatorship. We focus both mobilization processes and the reorganization of student centers after years of banishment. In this context, the reappearance of certain practices linked to the preceding decades combined with a critical assessment of the student movement on its recent past, under the new hegemony of Franja Morada which was influenced and also had an impact on the progress of Raul Alfonsin in his way to presidency and on the consolidation of a new "democratic ideal". Starting from these issues, this article aims to provide elements in order to establish a more complex relationship between factors of continuity and change in the early post-dictatorship years in Argentina.
\end{abstract}




\section{Introducción}

Tras sufrir con toda dureza las consecuencias del terrorismo de estado, el movimiento estudiantil reapareci ó en el escenario nacional entre mediados de 1982 y finales de 1983, incidiendo de diversas maneras en el proceso político que marcó la salida de la dictadura. Si por un lado sus movilizaciones formaron parte del ascenso de la conflictividad social que tiñó los últimos meses del gobierno de facto, por otro las elecciones de centros de estudiantes realizadas varios meses de antes de octubre de 1983 constituyeron un caso testigo hacia los comicios nacionales y expresaron los fuertes cambios políticos ocurridos tras más de siete años de represión dictatorial. En función de estas cuestiones, en este trabajo buscamos analizar la reactivación del movimiento estudiantil de la UBA entre 1982 y 1983 y su relación con la dinámica del conflicto social, del mundo universitario y de la política general de la Argentina en el final de la última dictadura.

Este artículo forma parte de nuestra investigación sobre el movimiento estudiantil universitario entre 1983 y 2001 que desarrollamos en el marco de una beca doctoral de la Universidad de Buenos Aires. En relación a ese período más extenso, el lapso que abordamos aquí es relativamente corto pero decisivo, ya que en él se delinearon varios de los rasgos que acompañarían al movimiento estudiantil durante las siguientes décadas.

Para el presente escrito nos basamos en distintas fuentes. En primer lugar, en la selección de recortes periodísticos relativos a temas universitarios del Archivo Histórico de la Universidad de Buenos Aires, junto a una serie de notas de diarios consultadas en la Hemeroteca de la Biblioteca del Congreso de la Nación. En segundo lugar, en fuentes primarias como volantes, plataformas y revistas de diversas agrupaciones, en particular de la Facultad de Filosofía y Letras, recopiladas por el Centro de Documentación "Universidad y Dictadura” de esa institución. Por último, en una serie de entrevistas a dirigentes estudiantiles de la época, realizadas por el autor o por otros investigadores. Planteamos un abordaje crítico de dichas fuentes, buscando compararlas entre sí y examinarlas a la luz de la bibliografía existente.

Cabe señalar que las referencias al movimiento estudiantil son muy reducidas en las diferentes investigaciones sobre la etapa postdicatorial. Por ejemplo, casi ninguno de los trabajos sobre la política argentina del período hace mención al mismo, ausencia que contrasta como veremos con sus permanentes apariciones en los medios de prensa de la época. Sólo en algunos casos se refiere a los estudiantes desde el peso creciente de la juventud y la Junta Coordinadora Nacional en la estructura del radicalismo (Altamirano, 1987; Novaro, 2009; Suriano \& Álvarez, 2013). Incluso son muy limitadas las menciones al movimiento estudiantil en los propios textos sobre la cuestión universitaria y educativa de esos años (Buchbinder \& Marquina, 2008; Chiroleu, 2005; Fernandez Lamarra, 2005). Son escasas también las producciones específicas sobre el movimiento estudiantil del período, con algunos trabajos que se concentran en los años anteriores y extienden a veces su análisis a los primeros momentos del gobierno de Alfonsín (Levenberg \& Marolla, 1988; Perel, Raíces \& Perel, 2006; Polak \& Gorbier, 1994; Toer, 1988)ํㅗ. En suma, el conocimiento sobre el movimiento estudiantil universitario a partir de 1982-1983 carece aún de un trabajo de investigación sistemático en relación a su dinámica política interna y su vínculo con la vida universitaria y política general de la Argentina.

\section{Debates y problemáticas en torno a la llamada transición democrática}

A partir de los a ños ' 80 , diversos autores estudiaron la restauración del orden constitucional en la Argentina bajo un marco común al que denominaron "transición a la democracia” (O’Donnell, Schmitter \& Whitehead, 1982; Nun \& Portantiero, 1987; Oszlak, 1984; entre otros). En términos de Portantiero (1987), este concepto no refiere a un "acto único" sino a un "proceso" con tres fases sucesivas: "crisis del autoritarismo", "instalación democrática” y "consolidación”. En esta breve síntesis se vislumbra uno de los ejes que vertebra los análisis sobre la "transición democrática": la dicotomía entre democracia y autoritarismo como matriz explicativa por excelencia, subsumiendo a otras tensiones o contradicciones sociales y políticas. $\underline{2}$ 
En los últimos años, algunos autores realizaron una evaluación crítica de estos conceptos. Por ejemplo, Cecilia Lesgart (2002) buscó historizar el surgimiento de los mismos señalando que para los intelectuales que los desarrollaron, "la democracia política y la transición a la democracia marcaron la constitución de una idea límite" cuya función fue delimitar el pasado, "lo no querido -el autoritarismo- o lo derrotado como proyecto de sociedad -la revolución socialista-”. Según Lesgart, el uso de las palabras democracia y autoritarismo fue "ambiguo y omniabarcativo" y tuvo "más valor histórico por su fuerza impulsora de nuevas realidades (teóricas y políticas) que por un riguroso y sistemático trabajo analítico y conceptual”. Para Lesgart entonces la construcción del concepto de transición a la democracia estaría indisolublemente ligada a un programa político (crítico tanto del autoritarismo como de las prácticas revolucionarias) $\underline{3}$ y la dicotomía democracia-autoritarismo resultaría insuficiente como eje articulador del análisis científico.

Por su parte, el trabajo de Feld y Franco (2015) buscó complejizar cierta linealidad en algunos estudios sobre el tránsito entre dictadura y democracia. Para las autoras, "los primeros tiempos de la llamada "transición a la democracia” constituyeron un momento mucho más abierto, incierto, ambiguo y lleno de continuidades y dilemas cuya resolución no era obvia ni evidente”. Feld y Franco también ponderan el tratamiento sobre el pasado reciente que predominó en los inicios de la posdictadura y su función política. En este sentido, sostienen que la “Teoría de los dos demonios” "no sólo indicaba una interpretación del pasado sino, quizá, más fundamentalmente, funcionaba como legitimadora del presente republicano y democrático que el radicalismo venía a refundar” (Feld \& Franco, 2015, p. 376).

En otras publicaciones recientes encontramos visiones diferentes entre sí. Por ejemplo, Marcos Novaro (2009, p. 23) plantea que "la sociedad argentina vio en la asunción de Raúl Alfonsín a la presidencia, cómo las vueltas de la historia le daban la oportunidad, nunca tan necesaria como entonces, de dejar atrás el pasado", mientras Ezequiel Adamovsky (2012) habla de la "democracia de la derrota”. Si el primero postula "la democracia como oportunidad", el otro enuncia por el contrario una suerte de "democracia sin oportunidades”, en el sentido de su vínculo inseparable con las políticas de la dictadura que la precedió. $\underline{4}$

Finalmente, el trabajo de M. M. Ollier (2009) recoge testimonios de ex militantes de izquierda, buscando graficar un paulatino abandono de las ideas revolucionarias y la emergencia de una "nueva cultura política" bajo el signo de la democracia. En este sentido el texto comparte cierta matriz con los primeros trabajos sobre la "transición” en relación a un camino gradual y en cierta medida unidireccional desde el pasado reciente hacia la posdictadura.

En definitiva, estos diversos debates y problemáticas nos interesan en función de dos nudos para el análisis del período. Uno tiene que ver con la relación entre elementos de continuidad y de cambio en los inicios de la posdictadura, tanto en cuanto a la dictadura saliente como a las ideas políticas de las décadas precedentes, particularmente aquellas ligadas a la necesidad de cambios revolucionarios. Indagaremos de qué manera se combinan en el movimiento estudiantil estos diversos aspectos en los meses estudiados. En segundo lugar, nos interesa dar cuenta de la interpretación del pasado reciente que los diferentes actores realizaron en esos momentos como punto de partida ineludible para legitimar prácticas políticas en ese presente. En particular, nos concierne abordar qué sostenía el movimiento estudiantil de principios de los ' 80 sobre aquel que lo había precedido en los años ’60 y '70.

\section{Las movilizaciones estudiantiles en el final de la dictadura}

A partir del golpe c ívico-militar de 1976, el gobierno de Jorge Rafael Videla prohibió la actividad política en las facultades, al tiempo que llevó adelante una política universitaria limitacionista y reaccionaria. $\underline{5}$ El terrorismo de estado se impuso con toda la fuerza en las universidades, con miles de detenidosdesaparecidos, asesinados y presos y el movimiento estudiantil sufrió una fuerte desestructuración. $\underline{6}$ Aún en 
esas condiciones, el estudiantado fue encontrando caminos de resistencia a la dictadura a través de expresiones puntuales, por lo general esporádicas y con una forma clandestina o semiclandestina, que crecieron hacia 1980 y 1981.

En 1982, la Guerra de Malvinas implicó un punto de quiebre, dando lugar a las primeras apariciones públicas del movimiento estudiantil, en principio con la colocación de una mesa en la entrada de cada Facultad para juntar donantes de sangre. La iniciativa aprovechó la contradicción entre la proscripción de la actividad estudiantil por parte de las autoridades universitarias y el contenido difícilmente censurable de esas primeras mesas (la solidaridad con los combatientes). Una vez instaladas, ya no habría marcha atrás: "primero la mesa no decía nada, a los veinte días decía Centro de Estudiantes de Ciencias Económicas y dos meses después estaba una bandera y las agrupaciones empezaban a volantear" ${ }^{2}$.

Tras la derrota en Malvinas, un contexto de renovada conflictividad social se sumó a la crisis política y económica en la salida del gobierno de facto y el inicio de la apertura política (Suriano \& Álvarez, 2013). En ese marco, a fines de 1982 se organizaron las primeras marchas y asambleas estudiantiles, y a principios de 1983 se produjo un verdadero estallido contra los cupos de ingreso a la Universidad con masivas manifestaciones en Buenos Aires, Córdoba, La Plata y Rosario. ${ }^{8}$ De este modo, un movimiento estudiantil que buscaba recomponerse se encontró súbitamente enriquecido con miles de aspirantes sin experiencia universitaria, pero que ahora se volcaban a la lucha.

Junto al rechazo al limitacionismo, los estudiantes cuestionaban los diferentes aspectos de la política universitaria de la dictadura. Los aranceles a la educación superior generaron su expresión más gráfica de repudio en la quema de las chequeras con las que se cobraban. Otros reclamos se ligaban a las malas condiciones de cursada, los concursos fraudulentos, la Ley Universitaria de 1980 y la supresión del cogobierno y la autonomía.

Por último, el fin de la proscripción y la represión, y la aparición con vida de los detenidos-desaparecidos se constituyeron en puntos nodales del programa. Los estudiantes fueron empalmando las reivindicaciones específicas a la consigna de que se termine la dictadura como expresa el cántico "Examen de Ingreso / Se va con el Proceso" entonado en las movilizaciones (Tiempo Argentino, 11/3/83). De igual modo, fueron confluyendo con otras organizaciones que enfrentaban al gobierno militar como las Madres de Plaza de Mayo. Todo este programa unificaba a la gran mayoría de las agrupaciones estudiantiles, constituyéndose un vasto frente antidictatorial.

En suma, las movilizaciones estudiantiles de 1982 y 1983 trascendieron las fronteras de la Universidad y fueron parte destacada del ascenso del conflicto social en el final de la dictadura. La falta de referencias al respecto en la bibliografía existente contrasta con su notoria presencia en los medios de prensa de la época, que entre agosto de 1982 y agosto de 1983 registraron 73 acciones diferentes de protesta y organización estudiantil en la $\mathrm{UBA}^{\underline{9}}$. Otro dato relevante es la preocupación que manifestaron en esos momentos las autoridades universitarias nacionales, como refleja la reunión de diez rectores con el Ministro de Educación para "tratar la creciente actividad política que desarrollan los centros estudiantiles en distintos puntos del

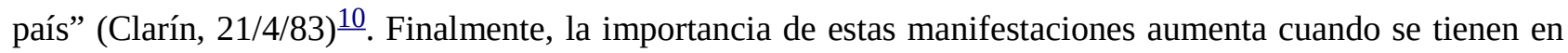
cuenta ciertas características del momento político desde fines de 1982:

Los partidos políticos, con escasas excepciones, intentaron irritar lo menos posible al régimen y les permitieron a las Fuerzas Armadas una buena dosis de iniciativa durante la transición. No obstante, el desprestigio y la propia incapacidad de los militares, la gravedad de la cuestión de los derechos humanos, el pronunciado malestar social y las voces más radicalizadas provenientes de la sociedad civil modificaron el devenir de los acontecimientos (...) (Suriano \& Álvarez, 2013, p. 150) 
El movimiento estudiantil debería incluirse dentro de esas voces que desafiaron a la dictadura e incidieron en las formas que adoptó la salida de la misma. En el plano específico de la educación superior, el conjunto de reivindicaciones estudiantiles que emergieron en esos meses influiría en la fisonomía de la Universidad en los inicios de la posdictadura, caracterizada por una expansión acelerada de la matrícula (Buchbinder \& Marquina, 2008).

\section{La reorganización de los centros de estudiantes}

En el marco de estas movilizaciones, los centros de estudiantes de la UBA fueron reorganiz ándose y realizaron sus primeras elecciones en más de siete años. En general, el punto de partida fue la creación de “comisiones pro centro", conformadas por representantes de las diferentes agrupaciones junto a activistas no agrupados. Estas comisiones convocaron a las primeras reuniones y también organizaron diversas iniciativas, desde la entrega de petitorios hasta la publicación de revistas. En algunas facultades se organizaron cuerpos de delegados y es particularmente llamativa la realización de asambleas como parte del proceso de normalización de la mayoría de los centros, algunas realmente masivas como en Derecho con 1500 estudiantes (ver Tabla 1). Cabe resaltar que aún regía el estado de sitio y era recurrente la presencia de personal policial en los pasillos, con lo que las asambleas tuvieron que sortear reiterados intentos de censura y persecución.

Tabla 1: Asambleas estudiantiles realizadas en Facultades de la UBA registradas por medios de prensa nacionales (agosto 1982-agosto 1983)

\begin{tabular}{|l|l|l|}
\hline Facultad o carrera & Fecha estimada & $\mathrm{N}^{o}$ estimado de estudiantes \\
\hline Ingeniería & $11 / 9 / 82$ & 200 \\
\hline Ingeniería & $1 / 10 / 82$ & 400 \\
\hline Exactas y Naturales & $5 / 10 / 82$ & S/D \\
\hline Medicina & $26 / 10 / 82$ & 400 \\
\hline Sociología & $3 / 11 / 82$ & 150 \\
\hline Farmacia y Bioquímica & $9 / 11 / 82$ & 400 \\
\hline Medicina & $18 / 11 / 82$ & 200 \\
\hline Económicas & $18 / 11 / 82$ & 500 \\
\hline Psicología & $7 / 4 / 83$ & 200 \\
\hline Derecho & $21 / 4 / 83$ & 1200 \\
\hline Sociología & $27 / 4 / 83$ & S/D \\
\hline Económicas & $27 / 4 / 83$ & S/D \\
\hline Filosofía y Letras & $5 / 5 / 83$ & 750 \\
\hline Derecho & $12 / 5 / 83$ & 1500 \\
\hline Medicina & $13 / 5 / 83$ & S/D \\
\hline Filosofía y Letras & $21 / 7 / 83$ & S/D \\
\hline
\end{tabular}

Fuente: Elaboración propia en base a relevamiento de notas periodísticas

La reaparición de estas formas de organización marca cierta continuidad con prácticas del movimiento estudiantil de los '60 y los '70, cuando los cuerpos de delegados y las asambleas constituyeron repertorios de organización recurrentes. La paulatina pérdida de estas instancias después de 1983 será un tema a investigar, pero podemos inferir a partir de su asiduidad en los meses estudiados que no podemos explicar dicha pérdida sólo como consecuencia directa de la represión de la dictadura sino de las propias ideas y la dinámica que 
irían predominando en la posdictadura. De hecho, dirigentes de dos de las principales agrupaciones de esos años, Franja Morada y UPAU, calificaban a las asambleas como “anacrónicas” (Toer, 1988). $\underline{11}$

Por otra parte, la realizaci ón de elecciones tras años de proscripción implicó un cambio para el movimiento estudiantil. La estructuración de una campaña electoral y el trabajo sobre corrientes de opinión a niveles más masivos supuso para las agrupaciones universitarias un formato distinto al de una movilización o asamblea y más aún a las prácticas clandestinas o semiclandestinas que prevalecían hasta poco tiempo atrás, generando contrapuntos en algunos casos. Por ejemplo, las agrupaciones vinculadas a la izquierda trotskista y maoísta tuvieron una participación activa en la reorganización de los centros pero su resultado electoral posterior fue magro, cuestión que desarrollaremos más adelante.

Las primeras elecciones se organizaron en noviembre de 1982 en los centros de estudiantes de Ingeniería, Psicología y Ciencias Exactas, mientras que entre mayo y septiembre de 1983 siguieron ese camino todas las facultades de la UBA. La importante participación estudiantil en estos comicios muestra el nivel de movilización y el clima de apertura política que se vivía (ver Tabla 2). Los reclamos estudiantiles se vieron potenciados por las elecciones de centros ya que ahora se trataba de centros estudiantiles legítimamente constituidos frente a autoridades universitarias que carecían de toda legitimidad. La preocupación del Ministerio de Educación en esos meses también debería leerse en esta clave.

Tabla 2: Cantidad de votantes y porcentaje de participación por centro de estudiantes (elecciones 1983)

\begin{tabular}{|l|l|l|l|}
\hline Centro de estudiantes & $\begin{array}{l}\text { Cantidad } \\
\text { votantes }\end{array}$ & $\begin{array}{l}\text { de } \\
\text { Padrón } \\
\text { estimado }\end{array}$ & $\begin{array}{l}\text { Participación } \\
\text { porcentual }\end{array}$ \\
\hline Económicas & $8173^{*}$ & 19900 & $41,1 \%$ \\
\hline Derecho & 7115 & 13000 & $54,7 \%$ \\
\hline Medicina & 5556 & 10000 & $55,6 \%$ \\
\hline Ingeniería & 5351 & 8000 & $66,9 \%$ \\
\hline Arquitectura y Urbanismo & $3996^{*}$ & 8000 & $49,9 \%$ \\
\hline Filosofía y Letras & $3105^{*}$ & 5800 & $53,6 \%$ \\
\hline Veterinaria & $1996^{*}$ & 4000 & $49,9 \%$ \\
\hline Agronomía & 1930 & 3600 & $53,6 \%$ \\
\hline Exactas y Naturales & $1928^{*}$ & 3500 & $55,1 \%$ \\
\hline Farmacia y Bioquímica & 1661 & 3000 & $55,4 \%$ \\
\hline Psicología & 1644 & 3200 & $51,4 \%$ \\
\hline Odontología & 1431 & 2000 & $71,6 \%$ \\
\hline Sociología & 444 & 650 & $68,3 \%$ \\
\hline Totales & $\mathbf{4 4 3 9 2}$ & $\mathbf{8 4 6 5 0}$ & $\mathbf{5 2 , 4 \%}$ \\
\hline
\end{tabular}

*No incluye votos en blanco e impugnados (carecemos de datos sobre los mismos) Fuente: Elaboración propia en base a relevamiento de notas periodísticas

De este modo, varios meses antes de las elecciones presidenciales del 30 de octubre de 1983, los centros de estudiantes contaban ya con autoridades electas, en algunos casos casi un año antes de aquellas. En un contexto donde se debatía y se marchaba a la restauración del sistema constitucional, las votaciones en las Facultades se convirtieron en un caso testigo de cara a los futuros comicios presidenciales.

\section{Las elecciones de centros como expresión de fuertes cambios políticos}

El elemento central que se desprende de los resultados de las primeras elecciones estudiantiles es un fuerte 
cambio pol ítico con respecto a las agrupaciones que dominaron el mapa universitario en buena parte de los años '60 y '70. Es manifiesta la hegemonía de Franja Morada, destacan las agrupaciones independientes y llama la atención la debilidad de las fuerzas de izquierda y el peronismo universitario (ver Tablas 3 y 4 ). $\underline{12}$

Tabla 3: Conducciones de centros de estudiantes de la UBA (elecciones 1983)

\begin{tabular}{|l|l|}
\hline Agronomía & LAI (Independientes) \\
\hline Arquitectura & Franja Morada \\
\hline Económicas & Franja Morada \\
\hline Exactas & Franja Morada \\
\hline Derecho & Franja Morada \\
\hline Farmacia & Lista Independiente \\
\hline Filosofía & Franja Morada \\
\hline Ingeniería & Franja Morada \\
\hline Medicina & Franja Morada \\
\hline Odontología & EIFO (Independientes) \\
\hline Psicología & JUI (Juv.Univ.Intransigente) \\
\hline Sociología & JUI \\
\hline Veterinarias & Franja Morada \\
\hline
\end{tabular}

Fuente: Elaboración propia en base a relevamiento de notas periodísticas

Tabla 4: Datos totales por agrupación o bloque (elecciones 1983)

\begin{tabular}{|l|l|l|l|}
\hline \multirow{2}{*}{ Agrupación o bloque } & $\begin{array}{l}\text { Porcentaje total de } \\
\text { votos }\end{array}$ & $\begin{array}{l}\text { Nro. de centros en } \\
\text { estimado }\end{array}$ & $\begin{array}{l}\text { Conducciones de } \\
\text { listas }\end{array}$ \\
\hline Franja Morada & $40,3 \%$ & 13 & 8 \\
\hline Independientes - MCEI & $23 \%$ & 10 & 3 \\
\hline JUI & $9,1 \%$ & 11 & 2 \\
\hline Independientes - BUIT & $7,6 \%$ & 7 & \\
\hline Peronismo universitario & $6,6 \%$ & 9 & \\
\hline MOR & $5,7 \%$ & 10 & \\
\hline MAS & $2 \%$ & 10 & \\
\hline Socialismo (MNR y otros) & $1,2 \%$ & 5 & \\
\hline UPAU & $1 \%$ & 1 & \\
\hline UJS & $1 \%$ & 6 & \\
\hline FAUDI & $0,3 \%$ & 4 & \\
\hline
\end{tabular}

Fuente: Elaboración propia en base a resultados por centro de estudiantes

Diversos medios de comunicación resaltaron el cambio que estos resultados representaban en las preferencias estudiantiles con respecto a las décadas precedentes. $\underline{13}$ Mientras La Nación (10/11/82) señalaba que "el resultado de esos comicios indica una crisis de los grupos de ultraizquierda (maoístas y trotskistas)", Clarín (19/6/83) se preguntaba en un titular “¿Ha nacido una nueva forma de 'hacer política' en la Universidad?” y sostenía de forma lisa y llana: “Los estudiantes afirman que ha terminado el tiempo de la virulencia partidista y que ahora pueden militar en un clima maduro y adulto”. 
Estos art ículos expresaban un clima general muy distinto al de fines de los '60 y principios de los '70, signado por fuertes manifestaciones obreras y populares, el ascenso de la izquierda y sectores del peronismo y la radicalización de la juventud. De algún modo, se hacían eco del fuerte retroceso sufrido por aquellos sectores tras casi ocho años de represión dictatorial y de un nuevo momento político en la Argentina y el mundo. $\underline{14}$

\section{La hegemonía de Franja Morada}

Franja Morada, brazo universitario de la UCR, fue la principal expresi ón estudiantil de este nuevo momento político y resultan ilustrativas las declaraciones de sus dirigentes en ese entonces. En la primera marcha pública de la Federación Universitaria Argentina (FUA) en 1982, su presidente Rodolfo Vázquez afirmaba que "es ridículo y malintencionado que se nos vincule con la subversión o con la Universidad del 73-74" (La Razón, 23/10/82), mientras Ariel Alegre, primer presidente del Centro de Estudiantes de Ingeniería (CEI), declaraba que "somos los primeros en señalar que no queremos nunca más la violencia en la Universidad" (La Nación, 8/11/82).

Estos testimonios expresan el núcleo de las concepciones de Franja Morada que predominaron dentro del estudiantado universitario en el '83: una crítica a la "violencia" unida a la necesidad de "superar el pasado" (términos que englobaban tanto al terrorismo de estado como a las organizaciones revolucionarias de los años '70) y un nuevo ideal, la democracia, como medio adecuado para resolver los reclamos de los estudiantes.

Este discurso empalmaba con las ideas que sostuvo Raúl Alfonsín en la campaña electoral de 1983, caracterizada por la "apelación a la democracia como la forma más legítima de resolución de problemas y conflictos” (Vommaro, 2006, p.262) y un planteo análogo en relación a “dejar atrás el pasado” en el marco de la "Teoría de los dos demonios". Como señala Marina Franco (2015, p. 66), "el acto mismo de enunciación de una matriz binaria a la salida de la dictadura [en relación a los “dos demonios”] la convertía en ternaria al incorporar un tercer lugar, el de quien la enunciaba, definido por su ajenidad frente al carácter demencial de los otros”.

No obstante, la pretendida superación del pasado se complejiza si se consideran declaraciones como las del primer Congreso de la Federación Universitaria de Buenos Aires (FUBA) en 1983, donde el presidente electo, Andrés Delich de Franja Morada, planteaba que "el enemigo aún acecha, pero los estudiantes de todos modos vamos a estar junto al pueblo para conquistar la liberación nacional y social de nuestra patria” (La Voz, 6/11/83). Estos términos parecerían asociados a la criticada militancia de los '60 y ' 70 . De hecho, Delich narra que "en 1983 operábamos con dos o tres documentos, uno es La contradicción fundamental, un viejo documento de los '70, filo maoísta, cuyo elemento central es la dialéctica pueblo-antipueblo (...) Seguía una matriz ideológica que tenía que ver con los $70 ” . \underline{15}$

Pero Delich precisa cómo integraban este tipo de ideas "heredadas” de los años “70 con la nueva realidad política:

Nosotros decíamos 'estamos todos de acuerdo en que tiene que haber un proceso de masas en la Argentina que irrumpa y transforme socialmente’ (...) Pero vos cuando hacías el discurso, terminabas siempre con esta otra reflexión política: ‘el radicalismo tiene para sí la idea de que le ha salvado la vida a muchos jóvenes que encontraron el camino de soñar un país distinto sin necesidad de la violencia armada y a través de la democracia'. (...) Entonces empalmamos perfecto en los ' 80 , con el clima de los ' $80 . \underline{16}$ 
Esta combinación de elementos podría complejizar la noción de un cambio de cultura política que habría llevado de la "revolución” a la “democracia”, tal como lo plantea M. M. Ollier (2009). Si en la mayoría de los testimonios que esta autora recoge encontramos un paulatino tránsito de ex militantes revolucionarios hacia las "ideas de la democracia”, aquí por el contrario vemos como una fuerza embanderada en la democracia como Franja Morada retoma elementos de la izquierda de los '60 y '70 e intenta absorberlos dentro de una nueva configuración dominante. Esta operación discursiva desde ya cambia sustantivamente el contenido de los planteos revolucionarios de los '60 y '70, pero muestra a la vez que 1983 no marca un abandono absoluto de aquellos conceptos. $\frac{17}{17}$

Es indudable que la hegemonía de Franja Morada en la UBA expresaba una percepción de los estudiantes no sólo con respecto a la realidad universitaria sino en gran medida sobre la política nacional. En el estudiantado universitario predominó ampliamente el optimismo con respecto a la apertura democrática y la figura de Raúl Alfonsín, y más aún en la Capital Federal donde la UCR obtuvo un 62\% de los sufragios. Teniendo en cuenta que las votaciones estudiantiles ocurrieron meses antes del triunfo radical a nivel nacional, los avances de Franja Morada no sólo se nutrieron del ascenso del alfonsinismo sino que colaboraron en su afianzamiento. Se produjo, en términos de Altamirano (1987, p. 317), un proceso de “interacción”: "la proyección nacional del líder de Renovación y Cambio (...) le abrió espacio a un militantismo organizado, de matriz universitaria, que amplificaba y le daba articulación orgánica, sobre todo entre los jóvenes, a esa proyección”.

El sector de la Junta Coordinadora Nacional, vinculado a Enrique Nosiglia, Federico Storani y Luis “Changui” Cáceres entre otros, encabezó dentro de la Juventud Radical este proceso, logrando niveles de adhesión que repercutirían también sobre la Universidad:

Nosotros fuimos al acto de Alfonsín en el 82 y de ahí salió una bolsa de consorcio así de este tamaño lleno de talones de gente joven que quería participar. Empezamos a clasificar y a llamar pero para armar la estructura de Alfonsín en la Capital Federal porque ese había pasado a ser nuestro eje político (...) El movimiento estudiantil estaba en segundo plano para nosotros en esa etapa, y vuelve con fuerza en el '83 con la figura de Alfonsín, y con todo lo que habíamos armado en los barrios. (...) Teníamos un torrente de gente que venía en el partido, no venía de la militancia universitaria. Yo armaba las listas, y decía por ejemplo quién tenemos para Veterinaria, mirá en la 15 hay 4, en la 12 hay tantos... $\underline{18}$

En estas declaraciones se visualiza un armado universitario con un fuerte componente externo, de afuera hacia dentro de las Facultades, ligado al ascenso de Alfonsín.

La relación con el candidato presidencial también terminó de definir la disputa interna de Franja Morada en la UBA a favor de la Coordinadora frente a la Corriente Nacional y Popular, orientada por Rubén Rabanal. Si esta última encabezó las listas en las tres elecciones estudiantiles de 1982, la Coordinadora terminó imponiendo su hegemonía en 1983 en la mayoría de los centros.

En suma, Franja Morada se transformó a la salida de la dictadura en la expresión estudiantil principal del nuevo momento político en la Argentina y su gravitación se prolongaría a lo largo de los años siguientes.

\section{El resto de las agrupaciones estudiantiles}

Otro elemento novedoso de las primeras elecciones universitarias de 1983 fue el de los independientes , con dos sectores diferenciados, referidos por varias fuentes como "independientes de derecha" e "independientes de izquierda”. El primer grupo conformó la "Mesa Coordinadora de Estudiantes Independientes” (MCEI), que logró la conducción de tres centros de estudiantes. Sus postulados eran “apolíticos” y en algunos casos 
sus dirigentes fueron vinculados con sectores de las autoridades universitarias del "Proceso". Por ejemplo la lista que ganó las primeras elecciones en Farmacia y Bioquímica "no hace ningún planteo acerca de la situación del país ni tiene programa al respecto, solamente menciona reivindicaciones locales” (La Voz, 3/6/83), mientras Nobis de Filosofía y Letras afirmaba: "queremos una Universidad al margen de todo activismo político, adoctrinamiento y desorden” $\underline{19}$. De este modo, este sector expresaba concepciones incubadas también durante años de dictadura: la idea de que era mejor distanciarse de la política y en el mejor de los casos atenerse a buscar mejoras en las condiciones de estudio.

Los "independientes de izquierda" agrupados en el "Bloque Universitario Independiente para la Transformación” (BUIT), aunque coincidían en postularse como "apartidarios”, impulsaban otro enfoque: "no entendemos por independiente un grupo apolítico, ni tampoco dedicado exclusivamente a la actividad gremial (...) buscamos la profunda politización y movilización del estudiantado”르. También tomaban posición sobre la relación entre Universidad y situación nacional: "buscamos formar una clara conciencia universitaria nacional y popular de contenido latinoamericanista y antioligárquico”. El fenómeno de las agrupaciones independientes es uno de los más interesantes y complejos del movimiento estudiantil de la UBA de las últimas décadas y 1983 marca un punto importante de su desarrollo.

En tercer lugar, en las elecciones estudiantiles del '83 tuvo peso la Juventud Universitaria Intransigente (JUI), vinculada al PI de Oscar Alende, que se impuso en Psicología y Sociología. La JUI se presentaba a sí misma como "izquierda democrática" (Toer, 1988), término que de un lado reivindicaba una posición progresista y del otro tomaba distancia de la izquierda de los años '70, en sintonía con el clima político dominante.

Por último, en 1983 hizo su aparición UPAU (Unión Por la Apertura Universitaria) agrupación vinculada a la Ucedé de Álvaro Alsogaray. Si bien en la primera ronda electoral sólo se presentó en Derecho, su peso crecería en los años sucesivos.

La contracara de estas agrupaciones en ascenso fueron las fuerzas, antes protagónicas, que vieron significativamente disminuida su incidencia dentro de la Universidad. El peronismo, integrado por diversos afluentes nucleados en el "Bloque Peronista Universitario" (BPU), no logró conducir ningún centro de estudiantes, contrastando con las cifras cercanas al 40\% de 1973 (Levenberg \& Marolla, 1988). En Filosofía y Letras, donde el Frente por una Universidad Nacional y Popular (FUNAP) era candidato al triunfo, la experiencia del tercer gobierno peronista y particularmente la llamada Ley Taiana fueron parte central del debate. A las críticas de Franja se sumaron las de fuerzas de izquierda que la denostaban por atentar "contra la autonomía y el cogobierno”르. Los volantes del FUNAP se manifestaban marcadamente a la defensiva:

Sabemos que esta ley, QUE NUNCA ENTRO EN PLENA VIGENCIA, es perfectible y que ciertos aspectos exigen una precisa revisión (...) Los gobiernos constitucionales (...) cometen errores, pero como estudiantes preferimos equivocarnos y salvar esos errores JUNTO A NUESTRO PUEBLO, y no "acertar siempre" en la soledad de las sectas [mayúsculas en el original]. $\underline{22}$

Es evidente que hacia 1983 predominó en el estudiantado una visión crítica del peronismo, que unificaba tanto su experiencia en el gobierno entre 1973 y 1976 como el accionar de la juventud peronista en la Universidad y en el país en aquellos años. En el mismo sentido, la campaña electoral de Alfonsín ubicaba al peronismo dentro del "pasado violento" que debía superarse. "El slogan radical 'Somos la vida', opuesto al peronista 'Somos la rabia', lo decía todo” (Adamovsky, 2012, p. 340).

Por su parte, el MOR (Movimiento de Orientación Reformista, vinculado al Partido Comunista) también vio 
disminuida su influencia. Todas las listas que integró tuvieron nombres como "Lista Unidad" o "Unidad Estudiantil”, que si expresaban su voluntad frentista a la vez diluían su perfil específico, quizá otra señal del poco favorable momento político. En un balance sobre las elecciones universitarias señalaban que "mirando el país real no es razonable pensar que los comunistas podamos concitar hoy como tales un grado de adhesión - respecto a los radicales por ejemplo - mayor que el logrado”르. El rendimiento electoral también fue menor al esperado en función de que contaban con un número importante de militantes en varias facultades, por ejemplo 11 “células” en Exactas. $\underline{24}$

Por último, la izquierda trotskista y maoísta mostró una marcada debilidad (MAS -Movimiento Al Socialismo-, UJS -vinculada al Partido Obrero- y FAUDI -orientado por el Partido Comunista Revolucionario-),aún cuando algunas fuerzas como el MAS mantenían cierto caudal de militantes, incluso mayor al de Franja Morada en facultades como Filosofía y Letras. $\underline{25}$ El MAS presentó listas en 10 de las 13 elecciones pero no logró superar el $2 \%$ de los votos totales, lo que refleja un contraste entre una fuerza militante considerable y una adhesión muy limitada en las urnas. Hay un contrapunto también entre la participación activa de estas fuerzas en las movilizaciones y asambleas previas (dirigentes del MAS, UJS y FAUDI aparecen junto a los de Franja y otras agrupaciones en las delegaciones que elevaban los pliegos al Ministerio de Educación) y la escasa cantidad de votos obtenida, expresión también de las dificultades que puede haberles traído el tránsito de las prácticas callejeras o asamblearias al armado de la campaña electoral. En cualquier caso, se evidencian los síntomas de la desestructuración tras años de terrorismo de estado y el declive de las ideas vinculadas a los cambios revolucionarios, la liberación y el socialismo. Recién a mediados de los '90, en una nueva situación, algunas de estas fuerzas lograrían disputar conducciones de centros de estudiantes en la UBA.

\section{La democracia como ideal dominante}

Si bien Franja Morada fue la expresi ón principal del nuevo momento político, la reivindicación de la democracia y la noción de "superar la violencia" teñían a gran parte del arco político estudiantil. Un dirigente de la Corriente de Estudiantes Peronistas de Filosofía y Letras afirmaba que

renegamos en todos sus términos de la Universidad de la violencia (...) a los funcionarios del Proceso no nos proponemos echarlos con los bombos ni con métodos violentos, sino con el plebiscito de todos los integrantes de la comunidad universitaria. Somos parte del peronismo responsable (Clarín, 8/6/83).

Otro estudiante, de la agrupación independiente Revalúo de Ciencias Económicas, planteaba “desterrar tanto la violencia característica de la Universidad del "73 al "76 como la falta de participación que signó la Universidad del proceso” (Clarín, 8/6/83). Un referente del PI reivindicaba “una serie de nuevos valores que habían ido naciendo a lo largo de los años de la dictadura, y que tenían que ver con un respeto mucho mayor por las relaciones democráticas” (Toer, 1988), mientras un dirigente del MOR expresaba que "el lado positivo es la mayor madurez que ganamos tan dolorosamente (...) nos dimos cuenta de que no queremos repetir las manifestaciones violentas del movimiento estudiantil” (Buenos Aires Herald, 17/6/83)

En definitiva, buena parte de las agrupaciones estudiantiles se plegó de uno u otro modo al clima dominante, colaborando en cierta manera con el ascenso de Franja Morada. Un hecho fundamental en este sentido fue el primer Congreso de la FUBA, en noviembre de 1983,donde Franja Morada, JUP, JUI, MOR, MNR y UPAU conformaron la Lista de Unidad Nacional como un "gran acuerdo de la democracia" (Levenberg \& Marolla, 1988). ${ }^{27}$ El principal dirigente de UPAU justificaba su participación en los mismos términos: "lo hicimos porque entendíamos que había que dar un aval a la lista que veíamos como la lista de la democracia” (Toer, 
1988).

Finalmente, la polémica con los “independientes de derecha", en algunos casos asociados a autoridades universitarias de la dictadura, potenció el discurso de Franja Morada como "garante de la democracia”. Más aún, la pervivencia de expresiones abiertamente reaccionarias como AUNAR (Acción Universitaria Argentina) que planteaba "no permitir que nuestra facultad vuelva a transformarse en el laboratorio de la subversión”르, servían de base al slogan del radicalismo: “Franja Morada o la cría del Proceso”.

En síntesis, no sólo la hegemonía de Franja Morada, sino gran parte de la dinámica política estudiantil en 1982 y 1983 expresó y colaboró a afianzar el nuevo "ideal democrático", constituyendo un eslabón del proceso político que desembocaría en el triunfo de Raúl Alfonsín en las elecciones presidenciales.

Volviendo a uno de los interrogantes planteados al comienzo de nuestro trabajo ¿qué interpretación hacía el movimiento estudiantil de 1983 sobre su propio pasado y qué peso tuvo esta interpretación en aquel momento? Los testimonios antes mencionados muestran que ciertas ideas que podían encontrar en Franja Morada su expresión más nítida, también eran enunciadas por otras agrupaciones. Muchas de ellas compartían de una u otra forma, una visión crítica del movimiento estudiantil que los precedía, particularmente de la experiencia de 1973-74 y la "violencia", pero extendiendo su crítica en definitiva al movimiento estudiantil de los ’60 y `70 en su conjunto. Esta visión sobre el pasado marcaba la apoyatura de las perspectivas a futuro, del horizonte político de buena parte de las agrupaciones estudiantiles $\underline{29}$.Una matriz dominante, como señala M. Franco (2015, p. 45) "estructurada en la idea de una ruptura -histórica y moralcon el pasado y en una nueva 'frontera', definida por su alteridad con el pretérito reciente”.

\section{Conclusiones}

La reorganizaci ón del movimiento estudiantil de la UBA entre 1982 y 1983 aporta elementos que enriquecen la investigación del período de salida de la dictadura en la Argentina, tanto en la dinámica específicamente universitaria como en su dimensión política más general.

En primer lugar, las fuertes manifestaciones estudiantiles en esos meses, con un contenido antidictatorial que trascendió la frontera de las facultades, constituyen un caso interesante de la conflictividad social que tiñó la retirada del gobierno de facto. Las movilizaciones contra el limitacionismo influirían hasta cierto punto en la fisonomía de la Universidad argentina en el período postdictatorial, caracterizada por un fuerte incremento de la matrícula.

En segundo lugar, la reorganización de los centros de estudiantes mostró la reaparición de prácticas vinculadas a los años ' 60 y '70 como los cuerpos de delegados y las asambleas, mientras la realización de elecciones implicó un terreno diferente para las agrupaciones tras años de proscripción. En un contexto donde se marchaba hacia los comicios presidenciales, las votaciones en las facultades constituyeron un caso testigo hacia el sufragio nacional.

Los resultados de esas elecciones expresaron los fuertes cambios políticos ocurridos en el movimiento estudiantil tras casi ocho años de dictadura, momento en que se combinaron diferentes elementos. Por un lado, las consecuencias del terrorismo de estado, la desestructuración de los centros de estudiantes, la reducción de la matrícula por el fuerte limitacionismo, la derrota de los sectores populares e incluso una nueva situación internacional, y a la vez la crisis de la dictadura, un nuevo auge de luchas sociales y la reorganización de los centros en un marco general de apertura política donde se gestaba un nuevo "consenso democrático”. En suma, un "clima de época” distinto al de los “60 y ’70, que dio lugar a una reconfiguración política. Si a nivel nacional el principal hecho que graficó estas transformaciones fue el triunfo de Raúl Alfonsín y la primera derrota del peronismo en elecciones presidenciales donde no estuviera proscripto, en la 
UBA el cambio se manifestó a partir de la nueva hegemonía de Franja Morada, el ascenso de los independientes y la caída de la izquierda y el peronismo. Al ocurrir meses antes de las elecciones presidenciales, los comicios estudiantiles fueron parte de ese proceso más general, incidiendo en él y a la vez recibiendo su influjo.

Franja Morada, brazo estudiantil de la UCR, fue la expresión principal de este nuevo momento político en la Universidad. Sus críticas a la violencia, su propuesta de "superar el pasado" de la mano de la "Teoría de los dos demonios” y la idea de la democracia como medio para conquistar reivindicaciones lograron expresar a una corriente mayoritaria de los estudiantes porteños. El avance de la Coordinadora se nutrió del ascenso de la figura de Raúl Alfonsín pero a la vez dotó a la campaña presidencial de una amplia base militante, novedosa para el radicalismo.

Por su parte, el nuevo fenómeno de las agrupaciones independientes reflejó concepciones también incubadas tras años de dictadura, como la idea de que no debía hacerse política en la Universidad impulsada por los “independientes de derecha”. Por su lado los "independientes de izquierda”, planteaban un enfoque apartidario pero no apolítico, mientras la JUI surgía como una izquierda respetuosa de los canales institucionales.

La contracara de estas fuerzas en ascenso fueron aquellas como el peronismo, el MOR y la izquierda maoísta y trotskista, protagónicas en los '60 y '70, que tras la dictadura militar sufrieron un fuerte retroceso. El peronismo se enfrentó a un estudiantado en el que prevaleció un balance crítico de las distintas experiencias de esa fuerza política en los años previos al golpe de estado. La izquierda por su parte logró un magro resultado electoral, aún cuando en algunos casos conservaba cierto caudal de militantes y había formado parte activa de la reorganización de los centros de estudiantes. Se pusieron de manifiesto en estos casos la dificultad para transitar desde las prácticas asamblearias o callejeras a las prácticas electorales y, más de fondo, la desestructuración tras años de terrorismo de estado y el declive de las ideas vinculadas a los cambios revolucionarios, la liberación y el socialismo.

La reorganización del movimiento estudiantil es un interesante caso de cómo vivió un sector de la sociedad la salida de la dictadura en la Argentina. Es indudable que entre los estudiantes predominó una sensación de optimismo con la democracia y con la figura de Alfonsín. Junto a Franja Morada, buena parte de las agrupaciones estudiantiles se plegaron al nuevo "ideal democrático", colaborando de ese modo en el afianzamiento de la hegemonía radical. En este sentido, en buena parte de estas agrupaciones predominó un balance crítico sobre el movimiento estudiantil de las décadas precedentes.

A modo de cierre, queremos destacar la relación compleja y contradictoria entre elementos de continuidad y de cambio que se manifiesta en todo este proceso. El resurgimiento de prácticas como las asambleas, la participación de fuerzas de izquierda en la reorganización de los centros y hasta ciertos aspectos heredados de los '70 en el propio discurso de Franja Morada ponen en cuestión, siguiendo a Feld \& Franco (2015), el “encanto arrasador (...) del 10 de diciembre de 1983 como refundación y punto cero”. Si estas autoras encuentran elementos de continuidad con el pasado dictatorial, aquí también los hallamos en relación a las ideas y prácticas de los sectores populares de las décadas anteriores. Al mismo tiempo, las primeras elecciones universitarias expresan fuertes cambios políticos, nuevas ideas dominantes que tiñen a buena parte de las agrupaciones y una nueva hegemonía de la mano de Franja Morada. Será importante analizar entonces cómo administró el movimiento estudiantil post-1983 el bagaje de los repertorios del pasado, ya no hegemónicos pero que sobrevivieron al terrorismo de estado, y que en muchos casos se manifestaban contradictorios con el nuevo clima dominante. En definitiva, la investigación del movimiento estudiantil posterior a 1983, muy marcado por la experiencia de los meses analizados, debería tener en cuenta toda la complejidad de este momento, más inicial que “fundante”. 


\section{Notas}

1 Por su parte, el libro de Mónica Beltrán (2013) aborda la historia de Franja Morada aunque sólo desde el punto de vista de esa agrupación y con un enfoque periodístico, mientras Ricardo Romero (1998) incluye referencias al período pero desde un encuadre relativamente superficial.

2 Portantiero (1987, p.257) prolonga este eje de análisis a toda la política argentina desde 1966: "Entre 1972 y 1976 nuestra sociedad, que buscaba salir de la situación autoritaria engendrada por el sueño mesiánico de la "Revolución Argentina” de 1966, encaró un proceso de transición a la democracia. Sabido es cuál fue su culminación: otro sueño autoritario se abatió, mucho más cruel, sobre un pueblo que había despilfarrado una oportunidad. Esa pesadilla duraría hasta principios de la década del '80, en que, a partir de la crisis de otro autoritarismo, volvería a abrirse la posibilidad de otra transición, en la que estamos hoy embarcados”

$\underline{3}$ De algún modo esta idea aparece de forma explícita en O’Donnell (1987, p.198) cuando afirma que: "Nuestro proyecto tuvo desde el principio una tendencia normativa, acompañada y reforzada por una generalización empírica. Hemos reconocido que la democracia política es deseable per se (...) los intentos de transformación revolucionaria no sólo fracasaron en su totalidad; también han sido un factor poderoso que condujo a la emergencia de regímenes autoritarios”.

4 El libro de Novaro y Palermo (2003) contiene afirmaciones más matizadas que la que citamos del primero. Los autores plantean por ejemplo los límites de los partidos políticos para tomar la iniciativa en los meses finales de la dictadura y sostienen que "la nueva época tenía demasiado de la vieja, y mucho de lo nuevo eran graves problemas por delante” (Novaro \& Palermo, 2003, p. 542).

$\underline{5}$ En relación al limitacionismo de la dictadura, los ingresantes a la UBA pasaron de cuarenta mil en 1974 a doce mil en 1981 y la cantidad de estudiantes bajó de 159.776 en 1975 a 106.981 en 1983. (Buchbinder, 2005)

6La "Misión Ivanissevich”, con un contenido limitacionista y autoproclamado “antimarxista”, había iniciado a partir de 1974 una fuerte persecución sobre el movimiento estudiantil universitario, que incluyó decenas de secuestros y asesinatos en la UBA, marcando un comienzo de la desestructuración de los centros de estudiantes.

Z Entrevista a Andrés Delich, realizada junto a Guadalupe Seia, en octubre de 2015

8 En el examen de ingreso de 1983 la UBA dispuso de 11.000 vacantes para 44.884 ingresantes (La Nación, 25/2/83). Terminarían ingresando sólo 8.065 estudiantes (Clarín, 23/4/83).

$\underline{9}$ Estos datos surgen de un listado elaborado a partir del relevamiento de artículos periodísticos en el Archivo Histórico de la Universidad de Buenos Aires. Incluye entre otros hechos: sentadas, asambleas y concentraciones en las facultades, denuncias públicas de los centros de estudiantes y manifestaciones al Ministerio de Educación. No contabilizamos aquí una importante cantidad de entrevistas y notas de análisis que acrecientan la presencia estudiantil en los medios.

10 El propio Ministro de Educación Cayetano Licciardo buscó justificar públicamente la continuidad de las políticas vigentes: "Yo no puedo creer que un estudiante de bien, un estudiante que realmente quiera entrar en la Universidad para estudiar, prefiera el ingreso irrestricto” (La Voz, 3/4/83). No obstante, en muchos casos los decanos y rectores se vieron forzados a otorgar concesiones, como la flexibilización de los cupos.

11 Podríamos vincular esta hipótesis con una idea de Novaro y Palermo (2003, p. 492) cuando plantean que "la democracia debía, para estabilizarse como orden perdurable, superar las doctrinas de la revolución, que parecían haber sobrevivido a los revolucionarios”. Si bien las asambleas no constituyen una práctica revolucionaria per se, sí se asociaban a los años ‘60 y ‘70, donde las ideas revolucionarias estaban en 
ascenso. De algún modo, la dinámica estudiantil hegemónica en la postdictadura fue deshaciendo después de 1983 esas prácticas que parecían haber sobrevivido también a la represión de la dictadura.

12 Un tema que excede las posibilidades de este trabajo son las condiciones socio-económicas y hasta políticas del estudiantado universitario de esos años, teniendo en cuenta las fuertes restricciones y la persecución de la dictadura. A partir de ello, su posible relación con los resultados electorales analizados.

13 En 1973 por ejemplo un balance nacional de las elecciones universitarias arrojaba un 24\% para la JUP, 23\% para Franja Morada, 22\% para el MOR-PC, 16,5\% para el FAUDI-TUPAC y 13\% para el MNR. En Buenos Aires, la JUP alcanzó ese año porcentajes cercanos al 40\%(Levenberg \& Marolla, 1987).Cabe señalar no obstante, que a partir de 1974, en el marco de la llamada "Misión Ivanissevich" y la fuerte persecución al movimiento estudiantil a la que referimos anteriormente, comenzaron a manifestarse cambios en la correlación de fuerzas de los centros de estudiantes. Franja Morada logró entonces un crecimiento de su influencia y en 1975 se alzó ya como segunda fuerza en los comicios estudiantiles de la UBA (Millán, 2015).

$\underline{14}$ Podríamos leer estos artículos a la luz de la idea de Adamovsky (2012) de una democracia teñida por la derrota de aquellos sectores.

15 Entrevista a Andrés Delich, realizada junto a Guadalupe Seia, en octubre de 2015.Efectivamente, en el texto "La contradicción fundamental" publicado por la Juventud Radical se define lo que sería el antagonismo básico de la sociedad argentina: "el pueblo argentino por un lado y el complejo antinacional oligárquico-monopólico-imperialista por el otro” (Junta Coordinadora Nacional, 1984). Altamirano (1987) también encuentra en él una "obvia filiación maoísta". Por otro lado, Aboy Carlés (2010) marca que la reedición de este documento en los '80, si bien mantuvo en lo principal su espíritu "setentista”, modificó algunas formulaciones clave, eliminando por ejemplo la palabra "revolución” o la idea de la construcción de una nueva sociedad "sobre bases socialistas".

16 Entrevista a Andrés Delich, realizada junto a Guadalupe Seia, en octubre de 2015.

17 Esta cuestión alumbra a su vez un nuevo aspecto de la "Teoría de los dos demonios". No sólo se equipara la violencia de organizaciones revolucionarias con la violencia de la dictadura, sin diferenciar como señala Franco (2015, p.33) que "uno de los demonios era el poder de fuego del Estado", sino que se manifiesta una supuesta adhesión a los ideales que habrían movido a las primeras, no sin cierta condescendencia, marcando siempre que estaban "equivocadas en los métodos". De este modo, no sólo se las critica duramente sino que a la vez se intenta apropiarse de cierto modo de algunas de sus banderas.

18 Ibídem.

19 Volante de Nobis en las elecciones del Centro de Estudiantes de Filosofía y Letras de la UBA (CEFyL) de 1983

20 Plataforma del Movimiento de Transformación Universitaria (MTU) en las elecciones del CEFyL de 1983.

$\underline{21}$ Volante de la Lista Unitaria UJS-GEI-MAS en las elecciones del CEFyL de 1983

$\underline{22}$ Volante de FUNAP en las elecciones del CEFyL de 1983

$\underline{23}$ Cuadernos Universitarios. Las elecciones estudiantiles, principal instrumento para la democratización universitaria. Publicación de la Federación Juvenil Comunista de abril de 1983.

$\underline{24}$ Ibídem. Cabe señalar que a diferencia de otras fuerzas de izquierda el Partido Comunista no había sido proscripto por la dictadura.

$\underline{25}$ Entrevista a Lucas Luchilo realizada en octubre de 2015. 
$\underline{26}$ En inglés en la publicación original: "the positive side is the greater maturity we have so painfully gained (...) we realice we don't want to repeat the violent demonstrations student movements"

$\underline{27}$ La confluencia de la mayor parte de estas fuerzas, cuya manifestación orgánica a nivel nacional fue la Multipartidaria, tuvo su correlato en el Movimiento de Juventudes Políticas (MOJUPO), que nucleaba a las juventudes de gran parte del arco político.

$\underline{28}$ Volante de AUNAR distribuido en la Facultad de Filosofía y Letras en noviembre de 1982.

$\underline{29}$ Como excepción podemos nombrar a una parte de los independientes, un sector del peronismo y la izquierda maoísta y trotskista, en general en clara minoría.

\section{Referencias bibliográfícas}

Aboy Carl és, G. (2010). Raúl Alfonsín y la fundación de la "segunda república”. En Gargarella, R., Murillo, M. V. \& Pecheny, M. (comps.). Discutir Alfonsín (pp. 67-84). Buenos Aires: Siglo XXI.

Adamovsky, E. (2009). Historia de la clase media argentina. Apogeo y decadencia de una ilusión, 19192003. Buenos Aires: Booket Planeta.

Adamovsky, E. (2012). Historia de las clases populares en la Argentina. Desde 1880 hasta 2003. Buenos Aires: Sudamericana.

Altamirano, C. (1987). La Coordinadora: elementos para una interpretación. En Nun, J. \& Portantiero, J. C. (comps.). Ensayos sobre la transición democrática en la Argentina (pp. 295-332). Buenos aires: Puntosur.

Beltrán, M. (2013). La Franja. De la experiencia universitaria al desafío del poder. Buenos Aires: Aguilar.

Buchbinder, P. (2005). Historia de las Universidades Argentinas. Buenos Aires: Sudamericana.

Buchbinder, P. \& Marquina, M. (2008). Masividad, heterogeneidad y fragmentación: el sistema universitario argentino 1983-2008. Buenos Aires: UNGS/Biblioteca Nacional.

Chiroleu, A. (2005). La Educación Superior en la agenda de gobierno argentina en veinte años de democracia (1983-2003). En Rinesi, E., Soprano, G. y Suasnábar, C. (comps.). Universidad, reformas y desafíos: dilemas de la educación superior en la Argentina y el Brasil (pp. 56-92). Buenos Aires: UNGS/Prometeo.

Feld C. \& Franco M. (dirs.) (2015). Democracia, hora cero. Actores, políticas y debates en los inicios de la posdictadura. Buenos Aires: Fondo de Cultura Económica.

Fernández Lamarra, N. (2002). Veinte años de educación en la Argentina. Balance y perspectivas. Buenos Aires: OREALC/UNESCO-EDUNTREF.

Franco, M. (2015) La “teoría de los dos demonios” en la primera etapa de la posdictadura. En Feld, C. \& Franco, M. (dirs.). Democracia, hora cero. Actores, políticas y debates en los inicios de la posdictadura (pp. 23-80). Buenos Aires: Fondo de Cultura Económica.

Gargarella, R., Murillo, M. V.\& Pecheny, M. (comps.) (2010). Discutir Alfonsín. Buenos Aires: Siglo XXI.

Junta Coordinadora Nacional, Juventud Radical (1984). La contradicción fundamental. En Cuadernos de Formación Política, núm. 1.

Levenberg, R. \& Marolla, D. (1988). Un solo grito. Crónica del movimiento estudiantil universitario de 1918 a 1988. Buenos Aires: FUBA. 
Lesgart, C. (2002). Usos de la transición a la democracia. Ensayo, ciencia y política en la década del ochenta. Estudios Sociales. N²2-23. Pp. 163-185

Millán M. (mayo, 2015). Franja Morada en la Universidad de Buenos Aires (1973-1976). Ponencia presentada en el VI Congreso Regional de Historia e Historigrafía, llevado a cabo en la Facultad de Humanidades y Ciencias de la Universidad Nacional del Litoral.

Novaro, M. (2009). Argentina en el fin de siglo: democracia, mercado y nación (1983-2001). Buenos Aires: Paidós.

Novaro, M. \& Palermo, V. (2003). La dictadura militar (1976-1983). Del golpe de estado a la restauración democrática. Buenos Aires: Paidós.

Nun, J. \& Portantiero, J. C. (comps.) (1987). Ensayos sobre la transición democrática en la Argentina. Buenos aires: Puntosur.

O’Donnell, G., Schmitter, P.C. \& Whitehead, L. (comps.). (1989) Transiciones desde un gobierno autoritario. Volumen 2, América Latina. Buenos Aires: Paidós.

O’Donnell, G. (1989). Introducción a los casos latinoamericanos. En O’Donnell, G., Schmitter, P.C. \& Whitehead, L. (comps.). Transiciones desde un gobierno autoritario. Volumen 2, América Latina (pp.15-36). Buenos Aires: Paidós.

Ollier, M. M. (2009). De la revolución a la democracia. Cambios privados, públicos y políticos de la izquierda argentina, Buenos Aires: Siglo XXI.

Oszlak, O. (comp.) (1984). “Proceso”, crisis y transición democrática. Buenos Aires: CEAL.

Perel, P., Raíces, E. \& Perel, M. (2006). Universidad y dictadura. Derecho, entre la liberación y el orden (1973/83). Buenos Aires: Ediciones del CCC.

Polak, L. \& Gorbier, J. C. (1994). El movimiento estudiantil argentino (Franja Morada 1976-1986). Buenos Aires: CEAL.

Portantiero, J. C. (1987). La transición entre la confrontación y el acuerdo. En Nun, J. \& Portantiero, J. C. (comps.). Ensayos sobre la transición democrática en la Argentina (pp. 257-293). Buenos aires: Puntosur.

Pucciarelli, A. (coord.) (2006). Los años de Alfonsín ¿El poder de la democracia o la democracia del poder? Buenos Aires: Siglo XXI.

Romero, R. (1998). La lucha continúa. El movimiento estudiantil argentino en el siglo XX. Buenos Aires: Eudeba/FUBA.

Suriano, J. \& Álvarez, E. (2013). 505 días que la Argentina olvidó. De la rendición de Malvinas al triunfo de Alfonsín. Buenos Aires: Sudamericana.

Vommaro, G. (2006). Cuando el pasado es superado por el presente: las elecciones presidenciales de 1983 y la construcción de un nuevo tiempo político en la Argentina. En Pucciarelli, A. (coord.). Los años de Alfonsín ¿El poder de la democracia o la democracia del poder? (pp. 254-282). Buenos Aires: Siglo XXI.

Toer, M. (1988). El movimiento estudiantil de Perón a Alfonsín (1946-1986). Buenos Aires: CEAL. 